"Published by Health Education Journal, 16 September 2010" Health Education, 111, 2, 117-132.

\title{
Smoking in Australian university students and its association with socio-demographic factors, stress, health status, coping strategies, and attitude
}

Jing Sun ${ }^{1}$, Nicholas Buys ${ }^{1}$, Donald Stewart ${ }^{1}$, David Shum ${ }^{1}$, Lynette Farquhar $^{1}$

${ }^{1}$ Griffith University, Brisbane, Australia

Word counts: 3978

Key words: Smoking, health, stress, coping strategies, attitude

\section{Authors:}

Dr Jing Sun (corresponding author)

School of Public Health, Griffith University

Logan Campus, University Drive, Meadowbrook, QLD 4131, Australia

Phone: 61733821198

Fax: 61733821034

j.sun@griffith.edu.au

Prof. Nicholas Buys

Health Group, Griffith University

Gold Coast campus, Griffith University, Parklands Drive, Southport, QLD 4215 Australia

Phone: 61755529280

Fax: 61755529025

n.buys@griffith.edu.au

Prof. Donald Stewart

School of Public Health, Griffith University

Logan Campus, University Drive, Meadowbrook, Queensland 4131, Australia

Phone: 61733821487

Fax: 61733821034

Donald.Stewart@griffith.edu.au

Prof. David Shum

School of Psychology, Griffith University

Mt Gravatt campus, Griffith University, QLD 4122, Australia

Phone: 61737353370

Fax: 61737353399

Email: d.shum@griffith.edu.au

Lynette Farquhar

Executive Officer for Deputy Vice Chancellor and Provost, Nathan campus, Nathan, Griffith University, QLD 4111, Australia 
Phone: 61737354406

Fax: 67137357507

Email: 1.farquhar@griffith.edu.au

Acknowledgement: The project was supported by Vice Chancellor Special Project Research Funding at Griffith University. The authors are grateful to all those students who participated and responded to the survey.

\section{Contributions of Authors:}

Author Jing Sun has designed the study and survey, contributed to the data collection, and drafted manuscript; Nicholas Buys has contributed to the study design, data collection, assisted with the draft manuscript and revised the manuscript; Donald Stewart contributed to the study design and edited the manuscript. David Shum has made primary contribution to the study design, data collection and interpretation of results. Lynette Farquhar has contributed to the study design and data collection 
Smoking in Australian university students and its association with sociodemographic factors, stress, health status, coping strategies, and attitude

\section{INTRODUCTION}

Tobacco use has been associated with negative health events and contributes to mortality and morbidity through conditions such as lung cancer, respiratory diseases, cancers of the upper respiratory and digestive tracts, ischemic heart disease, stroke and peptic ulcers (Mathers et al. 2001; Turrell and Mathers 2001; Turrell et al. 2006). Tobacco smoking is the single risk factor responsible for the greatest incidence of disease in Australia, providing around $12 \%$ of the total burden in Australian males and 7\% in females (Mathers, Vos, Stevenson andBegg 2001). The link between cigarette smoking and diseases is well known among middle-aged adults. However, the association between smoking and its related factors among young university students has not been extensively studied in an Australian sample.

There are a number of psychosocial factors linked to smoking initiation and smoking maintenance. Smokers often view smoking as an effective means of coping with minor and major stressful situations in daily life ( Khantzian, 1985; Koval, et al., 2000). Stress and associated distress or depression is an important factor in the adoption of smoking behaviour (Pritchard et al. 2007). Not only is current depression observed more often among smokers, but a lifetime history of depression or history of depressive symptoms has been associated with smoking cessation failure (Covey et al. 1998).

The association between chronic disease and smoking has been a point of some controversy. Tobacco exposure accounts for the vast majority of cases of lung 
cancer (U.S. Department of Health and Human Services 2004) and it appears that trends in lung cancer mortality follow general trends in smoking prevalence (Jemal et al. 2001; Mannino et al. 2001). Some studies indicate an association between tobacco smoking and heart disease, whereas others fail to show this connection (Paraskevas et al. 2009; Surinach et al. 2009).

Coping has been found to be related to smoking (Koval and Pederson 1999) and is defined as behaviours and thoughts individuals use to manage demands from the environment and to regulate stress-related emotions (Lazarus and Folkman 1984). Once smokers adopt smoking as a method for coping, it is possible they do not see the need to utilise less harmful active coping strategies. The stress-coping model of substance use model posits that the preference for coping through tobacco use instead of other strategies results from deficits in a person's repertoire of active and effective coping skills, such as efficacy and problem-solving. As a consequence, coping by substance leads to an increase in unresolved problems, which, in turn, contributes to a continuation of distress (Wills 1986).

Trends in smoking initiation in the United States suggest that knowledge of the health consequences of smoking has kept adults from starting to smoke (Gilpin et al. 1994). Adolescents' beliefs about potential health risks and personal approval of cigarette smoking have been found to be directly related to smoking behaviour (Halpern and Warner 1994). Several studies have demonstrated that knowledge alone does not directly translate into protective behaviours (Alam 2006; Vega et al. 1988), but knowledge is crucial because it influences and shapes self-efficacy beliefs, outcome expectations, normative beliefs, and perceptions of the severity of the health 
condition. In turn, these health beliefs influence our decision to engage in protective behaviours (Ajzen and Fishbein 1980; Rosenstock et al. 1988).

Although most studies have shown no differences in smoking rates between males and females (Johnson et al. 2001; Rigotti et al. 2000), a significant relationship has been found on the relationship between smoking and other variables such as the amount of money spent per week (more money is associated with greater likelihood of smoking), expectation of future smoking, stress, and perceived health (Koval, 2006). Several variables that were related to male smoking that include level of mastery (lower level ) and depression (higher level). For females, smokers were less likely to be involved in non-team based sports.

Data about the prevalence of tobacco use among young university students and the relationship of tobacco use with socio-demographic factors, morbidity and life stress measures in Australia are sparse. Instead our understanding of smoking behaviour has been derived from studies of adolescents in secondary schools and adult-population studies in America (Koval et al. 2006; Peterson et al. 2005). The association between cigarette smoking and morbidity and quality of life among university students, and difference in the prevalence of tobacco use between male and female, are therefore not well documented in Australia.

The present study was undertaken as part of a large multidimensional investigation of health and smoking behaviour of university students and involved three university campuses of a major university in Brisbane, Australia. It established an overall picture of life stressors, health and living conditions of the university students. This paper is 
based on data from this baseline survey. The aim of the study was to evaluate the prevalence of smoking in an urban university population and its association with socio-demographic factors, life stressors, physical health and mental health status, coping strategies, attitudes and knowledge about the effects of smoking on health. The following hypotheses were proposed:

1. Smoking is associated with life stressors, physical and mental health status, coping strategies, attitudes and knowledge about the effects of smoking on health.

2. The association between smoking and health and psychosocial factors differ in male and female university students.

\section{METHOD}

A cross-sectional investigation of university students aged 18 to 30 years was undertaken using a purposive sampling procedure. Students at three campuses of a major metropolitan University in Brisbane, Australia were invited to participate in the survey. A broadcast email was sent by the Deputy Vice Chancellor to all university students seeking their participation in completing an online survey. A follow up email was sent two weeks after the original email. Ten prize draws worth A $\$ 75$ each were offered as incentives to encourage students’ participation in the survey. Preliminary reports compared sampled student characteristics with those of the whole university students in order to ensure representativeness of the study sample. The online survey was conducted in August, 2009 and the study was approved by the Griffith University Human Research Ethics Committee (Ref number: PBH/24/09/HREC).

\section{Measures}


All participants completed an online survey administered via the email system at the University. Standardise instructions were provided to ensure consistency in data collection. The questionnaire was a structured self-report instrument and inquired about socio-demographic characteristics, current smoking behaviour, life stressors, physical and mental health status, and knowledge and attitudes about smoking. Coping strategies such as social support, disengagement coping, participation in social activities and exercise were also assessed.

Socio-demographic characteristics: The socio-demographic data collected were age, gender, marital status (divorced/married/widowed), ethnicity (Caucasian/Asian/others), monthly income in Australia dollars, and level of education based on years of schooling. Participants were asked to report their medical diagnosis as made by their doctors. Smoking habits were assessed by asking participants, “Do you currently smoke tobacco?' Answers for this question could be "Yes"' or "No"' and current smokers were defined as respondents reporting "Yes"' to this question. This is made clear to the respondents by including the following statement: "Current smokers are defined as those who either regularly or occasionally smoke tobacco, including manufactured cigarettes, roll-your-own cigarettes, cigars and pipes”.

Life Stressors: The Stress Scale (Clements \& Turpin, 1996) was used to measure life stressors. Each stress event is given a score that represents the amount of readjustment a person has to make in life as a result of the change. People with scores of 300 and higher have a high health risk. People scoring between 150 and 300 points have about a 50-50 chance of serious health change within two years. People scoring below 150 have a 1 in 3 chance of serious health change. This stress scale has a 
reasonable level of test-retest reliability with correlation coefficient level of 0.66 , and predictive validity of anxiety measured by General Health Questionnaire (Clement and Turpin 1996) with a correlation coefficient of 0.58 .

Mental and Physical Health: Health status was assessed through self report and included questions about physical illnesses such as, cardiac disease, respiratory disease, diabetes and hypertension, chronic obstructive pulmonary disease, hepatitis B or C, and cancer. Questions about mental health included depression, anxiety, eating disorder, schizophrenia, other form of psychosis, bi-polar disorder. Answers to those questions could be, 'No', 'Yes, diagnosed' (without prescription or a medical consultation), or 'Yes, treated' (with prescription and/or a medical consultation). All questions were answered through a 'yes' (yes with diagnosis/yes with treatment) or ‘no’ response.

Attitude and Knowledge: Attitude to smoking was evaluated by asking participants, “'Would you say your attitude to smoking is one of...” the following answers. Answers for this question could be “'strongly approve/approve/neither approve nor disapprove/disapprove/strongly disapprove’’. A further question explored this area: “How regularly are you affected by smoke on campus?”, with potential answers of “Rarely”, “Occasionally”, “Regularly”, “Often”. Knowledge of the effect of smoking on health is assessed by asking students, "Do you think the smoke from other people’s cigarettes on campus is harmful to you?”. The choice of answers for this question was: “Definitely yes”, “Probably yes”, “Probably no”, Definitely no”. Perception of the exposure to environmental smoke was assessed by two questions by asking: “Are 
you bothered or affected by smoke on campus?” Answers for this question could be "Yes" or "No".

Cope Strategies: Eight items from the COPE questionnaire (Carver et al. 1989) were chosen to assess two coping strategies "using emotional social support" and "tobacco use”. These two dimensions of COPE have a reasonable internal consistency with a Cronbach Alpha of 0.76 and 0.61 respectively (Carver, Scheier andWeintraub 1989). The questions showed a high level of predictive validity of self-esteem and locus of control. To reflect active coping strategies, two questions: "I join recreational activities, such as sports or exercise to get through it", "I participate in social activities such as choir, or church or volunteering organisations” were added to the COPE questionnaire. The alpha level of reliability of the two questions is 0.65 for the current study. The questionnaires used above showed validity coefficients are not affected by socio-demographic variables and particularly age, thus avoiding an age test bias.

Table 1 below confirms that the validity and reliability of the stress, COPE and attitude and knowledge scales have reached an adequate level for the current study sample. The content validity for the three scales is $49 \%, 81 \%$ and $57.58 \%$ of the variances explained respectively. The reliability of the stress scale, COPE, and attitude and knowledge scale are $0.73,0.94$, and 0.59 respectively.

\section{Insert Table 1}

\section{Statistical analyses}

We first determined the overall and by-gender group prevalence of current tobacco use (i.e., number of current tobacco cases divided by the total number of participants 
and numbers of current tobacco cases in a gender group divided by the total number in that gender group). Cross-tabulations were used to calculate frequencies and associations. Frequency comparisons between current tobacco use and each of the socio-demographic, mental and physical health variables were performed using ChiSquare $\left(\chi^{2}\right)$ tests for categorical variables. To identify factors associated with the dependent variable tobacco use, logistic regression analysis was chosen. In the multiple logistic regression, the initial model included all variables studied. Variables that were not associated with tobacco use $(\mathrm{P}<0.20)$ were excluded from the final regression model. The number of participants used in the statistical analysis varied due to missing data for some variables. The statistical analysis and 95\% confidence intervals (CIs) presented here were generated using the SPSS 16 program (SPSS Inc). Multivariate significance tests in the logistic regression analysis were carried out using the Hosmer-Lemeshow Goodness of Fit test. Statistical significance was evaluated using 2-tailed design-based tests.

\section{RESULTS}

\section{Response rate and sample characteristics}

A total of 18000 students including both undergraduate and postgraduate students in both full time and part-time mode who enrolled on three campuses in a main urban university in Brisbane, Australia were approached in the first round. 3413 students responded, yielding an overall response rate of $18.9 \%$, which is similar to other surveys of this kind (Rigotti et al. 1997). Among these respondents, there were 2417 students aged $18-30$, representing $70.8 \%$ of the university student population. The sample’s socio-demographic characteristics are presented in Table 2. These 
demographic variables were compared with the total university sample to ensure the representativeness of the study sample in gender, nationality, age and year level.

\section{Insert Table 2}

There were no significant differences between study sample and the total university student population in gender and nationality, but there were significant differences between these groups in age and student study year level. There was a smaller proportion of students aged less than 21 years and a higher proportion of freshman students in the study sample than that in the university population. Therefore, to control the confounding effect of age and student year level, these two variables were entered in the multivariate logistic regression model.

Women represented 73.4\%, domestic students 79.3\%, and undergraduate students $84.1 \%$ of the sample. Regarding educational level, $95.4 \%$ of the students had at least 12 years of schooling. Half of the students (53.1\%) received an annual income of less than $\$ 12,000$.

Table 3 shows the relationship between tobacco use and socio-demographic variables, physical health, mental health condition, coping strategies and attitudes towards smoking.

\section{Insert Table 3}

Rates of tobacco smoking were higher among students with lower levels of education (6.7\% for year 10 or lower vs. $4.8 \%$ for year 12 , $\mathrm{p}<0.001)$. Marital status was also related to smoking. Widowed (27.3\%), divorced (31.3\%) and separated (37.5\%) 
individuals were significantly more likely to be tobacco smokers than married (18.3\%) and unmarried (18.9\%) individuals. Bivariate analyses were used to identify associations between mental illness, physical illness, psychosocial factors and tobacco use. These indicated that university students who reported mental illness, felt not bothered by smoking, were rarely affected by smoke, felt smoking is less harmful, being male students, aged 21 to 30, and income level at 40K to 59,000 had higher rates of smoking compared to those who did not have these conditions. Furthermore, university students who smoke were more likely to use smoking to cope with life stressors, and had lower scores in using active coping strategies to deal with life stressors than students who did not smoke.

A logistical regression model was developed to identify factors independently related to current tobacco use. Due to the large number of inter-correlated predictor variables, a multivariate model was constructed to identify the most salient risk factors and the most parsimonious model for predicting the uptake of smoking. Factors that were not significant predictors in the bivariate analysis were not included in the final multiple logistic regression model. Following that, backward elimination was used to assess the importance of quadratic effects and first order interactions. Higher order interactions were not tested. Due to the large number of potentially important interactions a block reduction method was employed using a $1 \%$ significance level. By this method interactions were tested within and between each of the pairs of blocks jointly with all main effects but no other interactions present. After this initial elimination process all remaining interactions were entered into the complete model and elimination was allowed along with main effects. The final model consisted of 11 factors. The results are shown in Table 4. This consists of three 
models, with a general model that includes both male and female students, Model 1 for male students, and Model 2 for female students.

\section{Insert Table 4}

Table 4 shows the final results of the analyses with odds ratio (ORs) and 95\% CIs for current smoking and socio-demographic and health condition variables. In the general model, physical health, disengagement coping strategies, attitudes and beliefs in smoking, income were significant predictors of smoking, but not mental health indicators. Therefore Hypothesis 1 was partially supported.

In Model 1 for male university students, physical illness was a strong predictor of smoking, with males who had more than one chronic disease having a reduced chance ( $\mathrm{P}<0.001$ ) of smoking when compared with the healthy student group. Male students who felt they were occasionally affected by smoke were less likely (OR: 0.30, 95CI, 0.12-0.74) to smoke than those who reported not being affected by smoke in the environment. Model 1 also indicates that male students who think smoking is not harmful to people's health were eight times (95\% CI, 1.66-42.78) more likely to smoke than those who think smoking is definitely harmful.

Model 2 for female students indicates income was significantly related to females’ smoking. Women who had an income between $\$ 40,000$ to 59,999 had a four times greater likelihood of smoking than other income groups 
In both Model 1 and Model 2 for male and females, a disengagement coping strategy to stressors was again a strong predictor, with those who had tried to use such a coping strategy having a two times greater likelihood of taking up smoking (95\% CI: 1.82-2.27, $\mathrm{P}<0.001$ ) than those who did not use this strategy. Students with a 'strong approval' attitude toward smoking had a 10 to 41 times (OR=41 in males, 16 in females, $\mathrm{P}<0.05$ ) greater likelihood to be smokers than those who strongly disapprove of smoking behaviour. Students with an 'approval' attitude toward smoking have a 10 to 25 times (OR-10 in males, $\mathrm{P}<0.01$; 25 in females, $\mathrm{P}<0.01$ ) Students of taking up smoking; and students who had neutral attitudes to smoking had a higher chance $(\mathrm{OR}=18$ in males, $\mathrm{OR}=34$ in female; $\mathrm{P}<0.001)$ of being smokers than those who strongly disapprove of smoking behaviour. Females who indicated disapproval of smoking had a 6.08 times $(\mathrm{P}<0.001)$ likelihood of being smokers than students who show a 'strong disapproval' attitude. Knowledge of the effect of smoking on health is independently related to smoking conditions. Both male and female students who were not bothered by exposure to environmental smoke on campus were twice as likely (95\% CI: $1.82-2.27, \mathrm{P}<0.001)$ to be smokers than those who feel affected by passive smoking. Some of the variables which were significant in bivariate analyses did not contribute to the multivariate model in both males and females. Among these were mental illness, social support, and marital status

In summary, male and females students had a common pattern regarding to the relationship between smoking and health status and psychosocial factors such as health attitude and knowledge regarding the effect of smoking. They differed regarding to the relationship between smoking and stress, age and socioeconomic factors. Therefore, there is some support for Hypothesis 2. 


\section{DISCUSSION}

Current tobacco use rate for all participants (18.8\%), men (24.9.0\%) and women (16.6\%) in this sample indicates that smoking prevalence of tobacco use among Australian university students of both genders was similar to that found among young people in Australia (19\%) (AIHW, 2006). Smoking rates were higher among men than among women and peaked in the age group 26-30. Socio-demographic factors also associated with tobacco use in this sample were intermediate level of income (\$40,000 to $\$ 59,999)$. Having money to spend is an important predictor for females to take up smoking (Koval, Pederson andZhang 2006). but this is not the case for male students. The lack of effect on taking up smoking in the low income group (less than $\$ 40,000$ ) might because material hardship forces female students to cut expenses on cigarettes and stop smoking (Hymowitz et al. 1997; Townsend 1987), but this is not the case for male students.

Other researchers have suggested that smoking might serve as a coping mechanism through which people deal with life and environmental stress. The current study included a wide coverage of study and life stressors (Clement and Turpin 1996). In our study we have reported that lack of coping resources (ie., disengagement vs active coping) contributed directly to smoking behaviour in both male and female students, implying that increased vulnerability of students with poor coping skills is an important issue. The mediating varabile between smoking and variations in coping is the controllability of the stressor. When situations are controllable, active coping strategies predominate; when situations seem less controllable, alternative strategies are employed (Scheier et al. 1986) This association presumably should extend to 
dispositional variations in sense of control. People who report they typically could not cope are likely to use smoking and rely on such strategies as denial and disengagement of stressful situations.

The particular attitudes and knowledge profile of the smokers partly explained their higher odds of smoking behaviour. A better understanding of the environmental context for continued high rates of smoking among students is critical to developing interventions that reduce tobacco use in this population. We found that most smokers and almost half of non-smokers agree that smoking is acceptable among students.

People who believe that smoking does not have a harmful effect on health, or that exposure to environment smoking does not bother or affect them, had higher chance of smoking, indicating that for students aged 18-30, their attitude and beliefs towards smoking are important determinants of taking up smoking behaviour. Generally, nonsmokers demonstrate a more sophisticated knowledge of the relationship between smoking and health than smokers. This may be attributable to the salience to nonsmokers of the relationship between health and smoking behaviour, or it may also be an indicator of a perception within the university population of smoking as a behaviour that is overall detrimental to most aspects of health. While general population studies find that non-smokers are as knowledgeable or more knowledgeable than smokers relative to the relationship between smoking and heart disease (Weinstein et al. 2004), the findings of this study that university smokers are much less likely than non-smokers to understand the role of smoking in a number of diseases underpins the high prevalence of smoking in university. 
Tobacco use was not independently associated with psychiatric distress in this sample, a finding that is inconsistent with other clinical and community-based studies (Covey, Glassman andStetner 1998; Killen et al. 2003). Among those aged between 15 and 54 years and among those aged 18-year-old and over, psychiatric distress is usually associated with an increased chance of tobacco use of between 1.6 to 2 times (McClave et al. 2009). In contrast with other studies, in this sample, stress and psychiatric distress was not associated with smoking.

For students who have more than two physical illnesses in both male and female groups were less likely to smoke than healthy students suggesting that more then one physical conditions have made these students being more aware of the harmful effect of smoking on health than students who were either healthy or have only mild level of one physical condition.

There are a number of limitations of this study. First, we did not have longitudinal university level measurements, which may generate selection bias. The relationship between student characteristics and smoking may be due to the non-random selection for individuals into university and not because of university influences. Therefore, these relationships should be interpreted only as associations, not causal. Second, we did not measure the length of time that participants had smoked, thus we were not able to determine the cumulative effects of long time smoking on health. Third, other variables such as informal social control, availability of health services were not analysed into this paper, which may have limited the explanation of the effects of the multi-factorial university characteristics on smoking behaviours. 
CONCLUSION: It was shown in this study that stress, disengagement coping strategies, health attitude and knowledge regarding the effect of smoking are significant predictors of university students' smoking behaviour. It is recommended that active coping strategies, such as exercise and social participation, are probably better considered an important resource enabling a person to cope with smoking cessation and other stressors (Hanson et al. 1990). Future initiatives may need to focus on measures to increase students' coping strategies. A further implication of this study is that health education programs, which are designed to modify behaviour via a change in attitudes, beliefs and knowledge about the effects of smoking should be considered for implementation in university settings. 


\section{References}

Ajzen, I. and Fishbein, M. (1980). Understanding attitudes and predicting social behavioiur. Englewood Cliffs, NJ: Prentice-Hall.

Alam, A. A. (2006). "Knowledge of breast cancer and its risk and protective factors among women in Riyadh." Annals of Saudi Medicine Vol. 26 No. pp. 272-277.

Carver, C. S., Scheier, M. F., and Weintraub, J. K. (1989). "Assessing coping strategies: A theoretically based approach." Journal of Personality and Social Psychology Vol. 56 No. pp. 267-283.

Clement, K. and Turpin, G. (1996). "The life events scale for students: Validation for use with British samples." Personality Individual Difference Vol. 20 No. 6, pp. 747-751.

Covey, L., Glassman, A., and Stetner, F. (1998). "Cigarette smoking and major depression." Journal of Addictive Diseases Vol. 17 No. pp. 35-46.

Gilpin, E. A., Lee, L., Evans, N., and Pierce, J. P. (1994). "Smoking initiation rates in adults and minors: United States, 1944-1988." American Journal of Epidemiology Vol. 140 No. pp. 535-543.

Halpern, M. T. and Warner, K. E. (1994). "Differences in former smokers beliefs and health status folloiwng smoking cessation." American Journal of Preventive Medicine Vol. 10 No. pp. 31-37.

Hanson, B. S., Isacsson, S. O., Janzon, L., and Lindell, S. E. (1990). "Social support and quitting smoking for good. Is there an association? Results from the population study "Men born in 1914," Malmö Sweden. ." Addictive Behaviours Vol. 15 No. 3, pp. 221-233.

Hymowitz, N., Cummings, K. M., Hyland, A., Lynn, W. R., Pechacek, T. F., and Hartwell, T. D. (1997). "Predictors of smoking cessation in a cohort of adult smokers followed for five years." Tobacco Control Vol. 6 No. Suppl.2, pp. S57-S62.

Jemal, A., Chu, K. C., and Tarond, R. E. (2001). "Recent trends in lung cancer mortality in the United States." Journal of National Cancer Institute Vol. 93 No. pp. 277-283.

Johnson, L. D., O'Malley, P. M., and Warner, K. E. (2001). "Monitoring the future national survey results on drug use, 1975-2000." National Institute on Drug Abuse, Bethesda, MD.

Killen, J. D., Fortmann, S. P., Schatzberg, A., Hayward, C., and Varady, A. (2003). "Onset of major depression during treatment for nicotine dependence." Addict Behav. Vol. 28 No. 3, pp. 461-470.

Koval, J. J. and Pederson, L. L. (1999). "Stress-coping and other psychosocial risk factors: A model for smoking in grade 6 students

" Addictive Behaviors Vol. 24 No. 2, pp. 207-218.

Koval, J. J., Pederson, L. L., and Zhang, X. (2006). "Factors related to smoking in college and not in college young adults." American Journal of Health Education Vol. 37 No. 6, pp. 344-355.

Lazarus, R. S. and Folkman, S. (1984). Stress, appraisal, and coping. New York Springer.

Mannino, D. M., Ford, E., Giovino, G. A., and Thun, M. (2001). "Lung cancer mortality rates in brith cohorts in the United States from 1960 to 1994." Lung Cancer Vol. 31 No. pp. 91-99. 
Mathers, C. D., Vos, E. T., Stevenson, C. E., and Begg, S. J. (2001). "The burden of disease and injury in Australia." Bulletin of the World Health Organization Vol. 79 No. 11, pp. 1076-1084.

McClave, A. K., Dube, S. R., Strine, T. W., Kroenke, K., Caraballo, R. S., and Mokdad, A. H. (2009). "Associations between smoking cessation and anxiety and depression among U.S. adults." Addictive Behaviors Vol. 34 No. pp. 491497.

Paraskevas, K. I., Staghopoulos, V., Milkhailidis, D. P., and Perrea, D. (2009). "Smoking, abdominal sortic aneurysms, and ischemic heart disease: Is there is link?" Angiology Vol. 59 No. 6, pp. 664-666.

Peterson, N. A., Lowe, J. B., and Reid, R. J. (2005). "Tobacco outlet density, cigarette smoking prevalence, and demographics at the county level of analysis." Substance Use and Misuse Vol. 40 No. 11, pp. 1627-1635.

Pritchard, M. E., Wilson, G. S., and Yamnitz, B. (2007). "What redicts adjustment mmong college students? A longitudinal panel study." Journal of American College Health Vol. 56 No. 1, pp. 15-21.

Rigotti, N., FiFranza, J. R., Chang, Y., Tisdale, T., Kemp, B., and Singer, D. E. (1997). "The effects of enforcing tobacco-sales laws on adolescents' access to tobacco and smoking behaviour." New England Journal of Medicine Vol. 337 No. 15, pp. 1044-1051.

Rigotti, N., Lee, J. E., and Weehsler, H. (2000). "US college students use of tobacco products: results of a national survey." JAMA Vol. 284 No. pp. 699-705.

Rosenstock, I. M., Strecher, V. J., and Becker, M. H. (1988). "Social learning theory and the health belief model." Health Education Quarterly Vol. 15 No. pp. 175-183.

Scheier, M. F., Weintraub, J. K., and Carver, C. S. (1986). "Coping and stress: divergent strategies of optimists and pessimists." Journal of Personality and Social Psychology Vol. 51 No. pp. 1257-1264.

Surinach, a. L. R., Alvarez b, R., Coll, c. J. A., Carmona d, C., Snaclemente e, E., Aguilar f, M., Monreal, g., and Frena Investigators. (2009). "Diferences in cardiovascular mortality in smokers, past-smokers and non-smokers: Findings from the Frena registry." European Journal of Internal Medicine Vol. 20 No. pp. 522-526.

Townsend, J. L. (1987). "Cigarett tax, economic welfare and social class patterns of smoking." Applied Economics Vol. 19 No. pp. 355-365.

Turrell, G. and Mathers, C. (2001). "Socioeconomic inequalities in all-cause and specific-cause mortality in Australia: 1985-1987 and 1995-1997." International Journal of Epidemiology Vol. 30 No. 2, pp. 231-239.

Turrell, G., Stanley, L., de Looper, M., and Oldenburg, B. (2006). "Health inequalities in Australia: Morbidity, health behaviours, risk factors and health service use." Queensland University of Technology and the Australian Institute of Health and Welfare, Canberra.

U.S. Department of Health and Human Services. (2004). "The health consequences of smoking." U.S. Department of Health and Human Services, Centers for Disease Control and Prevention, National Center for Chronic Disease Prevention and Health Promotion, Office on Smoking and Health, Altanta.

Vega, W. A., Sallis, J. F., and Patterson, T. L. (1988). "Predictors of dietary change in Mexican American families participating in a health behaviour change program." American Journal of Preventive Medicine Vol. 4 No. pp. 194-199. 
Weinstein, N. D., Slovic, P., Waters, E., and Gibson, G. (2004). "Public understanding of the illnesses caused by cigarette smoking." Nicotine \& Tobacco Research Vol. 6 No. pp. 349-355.

Wills, T. A. (1986). "Stress and coping in early adolescence: Relationships to substance use in urban school samples." Health Psychology Vol. 5 No. pp. 503-529.

\section{Conflict of Interests:}

The authors declare that they have no conflicting interests. 
Table 1. Validity and reliability of Stress, COPE, and Knowledge and Attitude Scales for the current study sample.

\begin{tabular}{|c|c|c|c|c|}
\hline Scale & Scale & No of items & $\begin{array}{l}\text { \% of Variances } \\
\text { explained }\end{array}$ & $\begin{array}{l}\text { Reliability } \\
\text { (alpha level) }\end{array}$ \\
\hline Stress & & 31 & $46.88 \%$ & 0.73 \\
\hline $\begin{array}{l}\text { COPE } \\
(81.15 \% \\
\text { variances }\end{array}$ & Social support & 4 & $\begin{array}{l}36.42 \% \\
\text { in the COPE } \\
\text { scale }\end{array}$ & 0.91 \\
\hline $\begin{array}{l}\text { explained in } \\
\text { total, and } \\
\text { reliability }\end{array}$ & $\begin{array}{l}\text { Disengagement } \\
\text { coping }\end{array}$ & 4 & $\begin{array}{l}31.55 \% \\
\text { in the COPE } \\
\text { scale }\end{array}$ & 0.96 \\
\hline $\begin{array}{l}\text { alpha level is } \\
0.76 \text { ) }\end{array}$ & Active coping & 2 & $\begin{array}{l}13.17 \% \\
\text { in the COPE } \\
\text { scale }\end{array}$ & 0.65 \\
\hline $\begin{array}{l}\text { Attitude and } \\
\text { Knowledge }\end{array}$ & & 3 & $57.58 \%$ & 0.59 \\
\hline
\end{tabular}


Table 2. Sample's socio-economic characteristics

\begin{tabular}{|c|c|c|c|c|}
\hline Socio-economic variables & Study Sample & $\begin{array}{l}\text { University } \\
\text { sample } \\
\text { demographic } \\
\text { characteristics } \\
\mathrm{N}(\%)\end{array}$ & $\chi^{2}$ & $\mathrm{P}$ \\
\hline \multicolumn{5}{|l|}{ Gender } \\
\hline Female & 1775 (73.4) & $21833(58.8)$ & 0.11 & 0.49 \\
\hline Male & 639 (26.4) & $15276(41.2)$ & & \\
\hline \multicolumn{5}{|l|}{ Age } \\
\hline $18-20$ & 902 (37.4) & $14274(38.4)$ & 489 & $0.001 * * *$ \\
\hline $21-25$ & $1086(45.0)$ & $16671(44.9)$ & & \\
\hline $26-30$ & $426(17.6)$ & 3586 (9.7) & & \\
\hline \multicolumn{5}{|l|}{ Student year level } \\
\hline First year & $840(36.1)$ & $9227(25.90)$ & 199.87 & $0.001 * * *$ \\
\hline Second year & $453(19.4)$ & $7217(20.26)$ & & \\
\hline Third year & $666(28.6)$ & $8929(25.61)$ & & \\
\hline Postgraduate & $371(15.9)$ & 10255 (28.78) & & \\
\hline \multicolumn{5}{|l|}{ Nationality } \\
\hline Domestic students & $1783(79.3 \%)$ & 27088 (73.5\%) & 1.20 & 0.09 \\
\hline International students & 466 (20.8\%) & $9780(26.5 \%)$ & & \\
\hline \multicolumn{5}{|l|}{ Marital status } \\
\hline Never Married & $1727(79.2)$ & & & \\
\hline Widowed & $4 \quad(0.2)$ & & & \\
\hline Divorced & $12(0.6)$ & & & \\
\hline Separated but not & $14 \quad(0.6)$ & & & \\
\hline \multicolumn{5}{|l|}{ divorced } \\
\hline Married & 423 (19.4) & & & \\
\hline \multicolumn{5}{|l|}{ Qualification } \\
\hline Illiterate & $(0.2)$ & & & \\
\hline Year 9 or below & $21 \quad(0.9)$ & & & \\
\hline Year 10 & $(1.3)$ & & & \\
\hline Year 11 & $(2.1)$ & & & \\
\hline Year 12 & $2090(95.4)$ & & & \\
\hline \multicolumn{5}{|l|}{ Income } \\
\hline More than $\$ 60,000$ & (3.7) & & & \\
\hline $40 \mathrm{~K}-59,999$ & (6.3) & & & \\
\hline $12,000-39,999$ & $808 \quad(36.9)$ & & & \\
\hline Less than 12,000 & $1162 \quad(53.1)$ & & & \\
\hline
\end{tabular}

* Each variable shows different size due to missing information 
Table 3 Relationship between tobacco use and socio-economic and physical and mental health

\begin{tabular}{|c|c|c|c|c|c|}
\hline Variables & $\begin{array}{c}\text { Tobacco Use } \\
\text { No } \\
\text { N(\%) }\end{array}$ & $\begin{array}{c}\text { Tobacco use } \\
\text { Yes } \\
\text { N(\%) }\end{array}$ & Total & $\chi^{2}$ & $\begin{array}{c}\mathrm{P} \\
\text { value }\end{array}$ \\
\hline \multicolumn{6}{|l|}{ Mental illness } \\
\hline Non-cases & $1732(89.0)$ & $367(81.4)$ & 2099 & & \\
\hline 1 disease & $112(5.8)$ & $45 \quad(10.0)$ & 157 & 19.36 & 0.001 \\
\hline 2 or more diseases & 103 (5.3) & $39(8.6)$ & 142 & & \\
\hline \multicolumn{6}{|l|}{ Physical illness } \\
\hline Non-cases & 1476 (75.8) & $358(79.4)$ & 1834 & 3.29 & 0.19 \\
\hline 1 disease & $371(19.1)$ & $77(17.1)$ & 448 & & \\
\hline 2 or more diseases & $100(5.1)$ & 16 (3.5) & 116 & & \\
\hline \multicolumn{6}{|l|}{ Stress } \\
\hline No stress & $229(11.8)$ & 53 (11.8) & 282 & 4.91 & 0.18 \\
\hline Low level stress & $716(36.8)$ & $153(33.9)$ & 869 & & \\
\hline Medium level stress & 671 (34.5) & $149(33.0)$ & 820 & & \\
\hline High level stress & $330(17.0)$ & $96(21.3)$ & 426 & & \\
\hline $\begin{array}{l}\text { Social support coping } \\
\text { score M(SD) }\end{array}$ & $\begin{array}{l}10.49(3.48) \\
(n=1789)\end{array}$ & $\begin{array}{l}10.31(3.81) \\
(\mathrm{n}=399)\end{array}$ & 2188 & $* \mathrm{~T}=0.87$ & 0.38 \\
\hline $\begin{array}{l}\text { Disengagement coping } \\
\text { using cigarette M(SD) }\end{array}$ & $\begin{array}{l}4.18(1.12) \\
(n=1790)\end{array}$ & $\begin{array}{l}7.90(3.60) \\
(n=401)\end{array}$ & 2191 & $* \mathrm{~T}=-36.61$ & 0.001 \\
\hline Active coping $\mathrm{M}(\mathrm{SD})$ & $\begin{array}{l}3.79(1.59) \\
(\mathrm{n}=1808)\end{array}$ & $\begin{array}{l}3.53(1.48) \\
(\mathrm{n}=404)\end{array}$ & 2212 & $* \mathrm{~T}=3.01$ & 0.01 \\
\hline \multicolumn{6}{|l|}{ Attitude to smoking } \\
\hline Strong approval & $20(1.0)$ & 10 & 30 & & \\
\hline Approval & $22(1.1)$ & 37 (8.3) & 59 & 588.1 & 0.001 \\
\hline Neutral & 319 (16.5) & $285(63.9)$ & 604 & & \\
\hline Disapproval & $760(39.4)$ & $103(23.1)$ & 863 & & \\
\hline Strongly disapproval & 808 (41.9) & 11 (2.5) & 819 & & \\
\hline \multicolumn{6}{|l|}{ Bothered by smoking } \\
\hline Yes & 1157 (60.4) & $53(12.0)$ & 1210 & 484.2 & 0.001 \\
\hline No & 759 (39.6) & $390(88.0)$ & 1149 & & \\
\hline \multicolumn{6}{|l|}{ Affected by smoke } \\
\hline Rarely & $649(34.5)$ & $315(76.6)$ & 964 & 247.1 & 0.001 \\
\hline Occasionally & 709 (37.7) & $58(14.1)$ & 767 & & \\
\hline Regularly & 395 (21.0) & $32(7.8)$ & 427 & & \\
\hline Often & $130(6.9)$ & $6(1.5)$ & 136 & & \\
\hline \multicolumn{6}{|l|}{ Smoking is harmful } \\
\hline Definitely yes & $1121(58.2)$ & $133(30.1)$ & 1254 & & \\
\hline Probably yes & 609 (31.6) & $172(38.9)$ & 781 & 201.1 & 0.001 \\
\hline Probably not & $177(9.2)$ & 97 (21.9) & 274 & & \\
\hline Definitely not & $20 \quad(1.0)$ & $40(9.0)$ & 60 & & \\
\hline \multicolumn{6}{|l|}{ Gender } \\
\hline Female & 1472 (83.4) & $293(16.0)$ & 1765 & 25.73 & 0.001 \\
\hline Male & $474(75.1)$ & 157 (24.9) & 631 & & \\
\hline
\end{tabular}




\begin{tabular}{llllll}
\hline Age & & & & \\
$18-20$ & $775(86.8)$ & $118(13.2)$ & 893 & 30.7 & $\mathbf{0 . 0 0 1}$ \\
$21-25$ & $846(78.6)$ & $231(21.4)$ & 1077 & & \\
$26-30$ & $323(76.0)$ & $102(24.0)$ & 425 & & \\
Marital Status & & & & & \\
$\quad$ Never married & $1415(82.0)$ & $311(18.0)$ & 1726 & 10.03 & $\mathbf{0 . 0 4}$ \\
Widowed & $3 \quad(75.0)$ & $1(25.0)$ & 4 & & \\
Divorced & $9 \quad(75.0)$ & $3(25.0)$ & 12 & \\
$\quad$ Separated & $7(50.0 \%)$ & $7(50.0)$ & 14 & \\
$\quad$ Married & $347(82.0)$ & $76(18.0)$ & 423 & \\
Ethnicity & $1441(81.2)$ & $333(18.8)$ & 1774 & 2.00 & \\
Domestic & $378(80.5)$ & $81(18.3)$ & 459 & \\
International & & & & \\
Income & $64(78.0)$ & $18(22.0)$ & 82 & 29.00 \\
$\quad$ More than $\$ 60,000$ & $97(70.3)$ & $41(29.7)$ & 138 & \\
40K-59,999 & $634(78.6)$ & $173(21.4)$ & 807 & \\
12,000-39,999 & $993(85.5)$ & $169(14.5)$ & 1162 & \\
$\quad$ Less than 12,000 & & & & \\
\hline
\end{tabular}


Table 4 Logistic Regression analysis of tobacco use and socio-economic and physical and mental health factors among university students $(n=3500)$.

\begin{tabular}{|c|c|c|c|c|c|c|c|c|c|}
\hline \multirow[b]{2}{*}{ Variables } & \multicolumn{3}{|c|}{$\begin{array}{l}\text { General model } \\
\quad(\mathrm{N}=2417)\end{array}$} & \multicolumn{3}{|c|}{$\begin{array}{c}\text { Model } 1 \\
\text { Males } \\
(n=631)\end{array}$} & \multicolumn{3}{|c|}{$\begin{array}{c}\text { Model } 2 \\
\text { Females } \\
(n=1765)\end{array}$} \\
\hline & $\begin{array}{l}\text { Odds } \\
\text { Ratio }\end{array}$ & $95 \% \mathrm{CI}$ & $\begin{array}{l}\mathrm{P} \\
\text { Value }\end{array}$ & OR & $95 \%$ CI & $\mathrm{P}$ & OR & $95 \%$ CI & $\mathrm{P}$ \\
\hline \multicolumn{10}{|l|}{ Mental illness } \\
\hline Non-cases (ref) & 1 & 1 & & 1 & 1 & & 1 & 1 & \\
\hline 1 disease & 0.83 & $(0.44-1.57)$ & 0.56 & 1.28 & $(0.21-8.08)$ & 0.79 & 0.77 & (0.31-1.93) & 0.77 \\
\hline 2 or more & 1.06 & $(0.55-2.06)$ & 0.85 & 0.62 & $(0.07-5.61)$ & 0.67 & 1.60 & $(0.63-4.04)$ & 0.32 \\
\hline \multicolumn{10}{|l|}{ Physical illness } \\
\hline Non-cases & 1 & 1 & & 1 & 1 & & 1 & 1 & \\
\hline 1 disease & 0.89 & $(0.63-1.23)$ & 0.47 & 1.03 & $(0.38-2.82)$ & 0.96 & 0.80 & $(0.45-1.44)$ & 0.46 \\
\hline 2 or more diseases & 0.14 & $(0.04-0.45)$ & 0.01 & 0.04 & $(0.002-0.97)$ & 0.05 & 0.22 & $(0.06-0.76)$ & 0.02 \\
\hline \multicolumn{10}{|l|}{ Stress } \\
\hline No stress & 1 & 1 & & 1 & 1 & & 1 & 1 & \\
\hline Low level & 2.17 & $(0.82-5.73)$ & 0.12 & 3.33 & $(0.62-17.84)$ & 0.16 & 1.36 & $(0.38-4.81)$ & 0.63 \\
\hline Medium level & 2.37 & $(0.89-6.28)$ & 0.08 & 2.86 & $(0.53-15.33)$ & 0.22 & 1.79 & $(0.51-6.27)$ & 0.36 \\
\hline High level & 2.18 & $(0.78-6.13)$ & 0.14 & 1.68 & $(0.27-10.61)$ & 0.38 & 1.91 & $(0.50-7.23)$ & 0.34 \\
\hline Disengagement coping & 1.94 & $(1.76-2.14)$ & 0.001 & 1.75 & $(1.50-2.04)$ & 0.00 & 2.18 & $(1.89-2.52)$ & 0.00 \\
\hline Active coping & 0.94 & $(0.823-1.06)$ & .326 & 0.91 & $(0.72-1.15)$ & 0.43 & 1.00 & $(0.86-1.17)$ & 0.98 \\
\hline \multicolumn{10}{|l|}{ Attitude on smoking } \\
\hline Strongly approval & 23.49 & $(5.83-94.73)$ & 0.001 & 41.72 & $(4.32-402.99)$ & 0.001 & 16.16 & (1.54-169.85) & 0.00 \\
\hline Approval & 15.13 & $(4.68-48.90)$ & 0.001 & 10.98 & $(2.01-59.86)$ & 0.01 & 25.06 & (4.30-146.18) & 0.01 \\
\hline Neutral & 25.06 & $(11.04-56.88)$ & 0.001 & 18.43 & $(4.87-69.75)$ & 0.00 & 34.95 & (11.61-105.22) & 0.00 \\
\hline Disapproval & 4.60 & $(1.99-10.60)$ & 0.001 & 3.61 & $(0.91-14.42)$ & 0.07 & 6.08 & $(2.00-18.52)$ & 0.00 \\
\hline
\end{tabular}




\begin{tabular}{|c|c|c|c|c|c|c|c|c|c|}
\hline $\begin{array}{l}\text { Strongly disapproval } \\
\text { Is bothered by smoking }\end{array}$ & 1 & \multicolumn{2}{|l|}{1} & 1 & \multicolumn{2}{|l|}{1} & 1 & 1 & \multirow[b]{3}{*}{0.004} \\
\hline Yes (refs) & 1 & 1 & & 1 & 1 & & 1 & 1 & \\
\hline No & 2.76 & $(1.61-4.74)$ & 0.001 & 2.96 & $(1.05-8.35)$ & 0.04 & 2.68 & $(1.38-5.22)$ & \\
\hline \multicolumn{10}{|l|}{ Affected by smoking } \\
\hline Rarely (Ref) & 1 & 1 & & 1 & 1 & & 1 & 1 & \\
\hline Occasionally & 0.36 & $(0.22-0.60)$ & 0.001 & 0.30 & $(0.12-0.74)$ & 0.01 & 0.38 & $(0.21-0.72)$ & 0.01 \\
\hline Regularly & 0.46 & $(0.21-0.98)$ & 0.04 & 0.59 & (0.17-2.07) & 0.41 & 0.34 & $(0.13-0.99)$ & 0.47 \\
\hline All the time & 0.38 & $(0.10-1.44)$ & 0.16 & 0.63 & $(0.12-3.30)$ & 0.58 & 0.18 & $(0.01-2.20)$ & 0.18 \\
\hline \multicolumn{10}{|l|}{ Smoking is harmful } \\
\hline Definitely yes (Refs) & 1 & 1 & & 1 & 1 & & 1 & 1 & \\
\hline Probably yes & 1.02 & $(0.71-1.47)$ & 0.92 & 0.96 & $(0.44-2.12)$ & 0.92 & 0.96 & $(0.43-2.12)$ & 0.92 \\
\hline Probably no & 1.20 & $(0.77-1.88)$ & 0.43 & 1.29 & $(0.54-3.09)$ & 0.21 & 1.29 & $(0.54-3.09)$ & 0.57 \\
\hline Definitely no & 3.86 & $(1.51-9.91)$ & 0.001 & 8.42 & (1.66-42.78) & 0.001 & 1.90 & $(1.53-6.83)$ & 0.32 \\
\hline \multicolumn{10}{|l|}{ Income (first) } \\
\hline Less than 12,000 & 1 & 1 & & 1 & 1 & & 1 & 1 & \\
\hline $12,000-39,999$ & 1.72 & $(0.77-3.83)$ & 0.18 & 0.77 & $(0.12-4.87)$ & 0.78 & 2.71 & $(0.59-12.54)$ & 0.12 \\
\hline $40 \mathrm{~K}-59,999$ & 2.16 & $(1.08-4.30)$ & 0.03 & 1.31 & $(0.26-6.56)$ & 1.31 & 4.18 & (1.07-16.29) & 0.04 \\
\hline More than $\$ 60,000$ & 1.37 & $(0.68-2.78)$ & 0.38 & 0.75 & $(0.14-3.82)$ & 0.73 & 2.33 & $(0.59-9.27)$ & 0.10 \\
\hline \multicolumn{10}{|l|}{ Age } \\
\hline $18-20$ & 1 & 1 & & 1 & 1 & & 1 & 1 & \\
\hline $21-25$ & 1.15 & $(0.73-1.82)$ & .563 & 1.20 & $(0.51-2.83)$ & 0.68 & 1.14 & $(0.68-1.94)$ & 0.60 \\
\hline \multirow[t]{2}{*}{$26-30$} & 1.24 & $(0.71-2.17)$ & .500 & 0.63 & $(0.23-1.74)$ & 0.37 & 1.68 & $(0.61-2.51)$ & 0.55 \\
\hline & \multicolumn{3}{|c|}{$\mathrm{R}$ square $=65.6 \%$} & \multicolumn{3}{|c|}{$\begin{array}{l}\text { R square }=64.0 \% \text {, Classification } \\
\text { correct rate: } 90 \%\end{array}$} & \multicolumn{3}{|c|}{$\begin{array}{l}\text { R square }=65.6 \% \text {, } \\
\text { Classification correct rate }=92.6 \%\end{array}$} \\
\hline
\end{tabular}

